Research article

\title{
Imiquimod for the treatment of genital warts: a quantitative systematic review R Andrew Moore ${ }^{* 1}$, Jayne E Edwards ${ }^{1}$, Jennie Hopwood ${ }^{2}$ and David Hicks ${ }^{3}$
}

\author{
Address: ${ }^{1}$ Pain Research and Nuffield Department of Anaesthetics University of Oxford, The Churchill, Headington Oxford OX 3 7 LJ, UK, \\ ${ }^{2}$ Chlamydia Pilot Office, Academic Unit, St Catherine's Hospital, Tranmere, Birkenhead, Wirral, UK and ${ }^{3}$ Department of GU Medicine, Royal \\ Hallamshire Hospital, Sheffield S10 2JF, UK \\ E-mail: R Andrew Moore* - andrew.moore@pru.ox.ac.uk; Jayne E Edwards - jayne.edwards@ru.ox.ac.uk; \\ Jennie Hopwood - drHopwood@aol.com; David Hicks - DAHsheff@aol.com \\ ${ }^{*}$ Corresponding author
}

Published: 5 June 200I

BMC Infectious Diseases 200I, I:3

This article is available from: http://www.biomedcentral.com/I47I-2334/I/3

(c) 200 I Moore et al, licensee BioMed Central Ltd.
Received: 6 April 2001

Accepted: 5 June 2001

\begin{abstract}
Objective: To review published randomised controlled trials to assess the benefit and harm of imiquimod in the treatment of external genital warts.
\end{abstract}

Data sources: MEDLINE (I 966 - December 2000), Cochrane Library (Issue 3, 2000) and PubMed (December 15, 2000), review articles and reference lists.

Review methods: Included studies had to be randomised trials of imiquimod, to be full published papers, and to have a comparison group. Quality of trial reporting was assessed. Relative benefit and number needed to treat were calculated for the main outcomes of wart clearance at the end of therapy, of at least $50 \%$ reduction in wart area, and of complete clearance at the end of treatment and no recurrence of warts during a follow-up period, as well as for adverse effect withdrawal or lack of efficacy withdrawal.

Results: There were six trials, all with quality scores of 3 (out of 5) or greater. In five trials with HIV-negative patients complete clearance of warts at the end of treatment occurred in $51 \%$ of patients treated with imiquimod $2 \%$ or $5 \%$ cream and $6 \%$ of placebo treated patients. The number needed to treat was 2.2 (95\% confidence interval 2.0 to 2.6 ). In four trials at least $50 \%$ wart area reduction occurred with $72 \%$ of patients treated with imiquimod $5 \%$ cream and $20 \%$ of placebo treated patients. The number needed to treat was 1.9 ( 1.7 to 2.2 ). In three trials complete clearance of warts at the end of treatment plus no recurrence occurred in $37 \%$ of patients treated with imiquimod $5 \%$ cream and $4 \%$ of those treated with placebo. The number needed to treat was 3.0 (2.5 to 3.8). Adverse event withdrawal was rare and no more likely with imiquimod than with placebo. Imiquimod was not effective in one trial in HIV-positive patients.

Conclusion: The evidence base for imiquimod in treating genital warts is of high quality and the necessary size from which to draw useful conclusions. Imiquimod is effective in home application, though not in patients with HIV infection with the evidence presently available.

\section{Introduction}

External genital warts are common. In the UK in 1998 there were 111,000 reported new cases in clinics of genitourinary medicine [1]. Genital warts are the commonest sexually transmitted infection, affect mainly younger people, and usually caused by human papillomavirus genotypes 6 or 11. These genotypes are not normally involved with cancers. Association with human papilloma- 
virus genotypes 16 and 18 can give rise to subclinical lesions associated with cervical intraepithelial neoplasia and squamous cancer.

A variety of methods have been used to treat external genital warts, and the primary goal of treatment before 1997 was the physical removal of symptomatic warts [2]. Methods used included excision, laser vaporisation, electrocautery, cryotherapy, caustic agents like trichloroacetic acid, podophyllin resin and intralesional interferon. Many of these are painful, which may result in undertreatment, whilst overtreatment can cause scarring or other complications. These treatments can also be expensive, as a number of outpatient visits may be required for a satisfactory result [2], and many have high rates of recurrence [2].

Guidelines for diagnosis and treatment have been published [3] and promulgated [4]. These guidelines are themselves based on earlier advice in the UK [5] and USA $[6,7]$. The involvement of primary care physicians in the treatment of genital warts is increasingly encouraged [4]. Choice of therapy depends on morphology of, and extent of the warts, as well as patient and professional choice, as outlined in a treatment algorithm used in Los Angeles [2]. Availability and cost may also be considerations. There are two choices for home treatment, imiquimod and podophyllotoxin gel [6].

This systematic review was performed in order to quantify the benefits and harms of imiquimod, and to provide fuller information upon which choice can be based. The intention was, where possible, to pool information on important clinical outcomes and to generate not only statistical significance between imiquimod and control, but also to provide measures of treatment efficacy, such as numbers needed to treat (NNT). NNT is treatment specific. It describes the difference between active treatment and control in achieving a particular clinical outcome [8]. Low NNTs indicate high treatment-specific efficacy. An NNT of 1 says that a favourable outcome occurs in every patient given the treatment but in no patient in a comparator group. This would be the 'perfect' result in, say, a therapeutic trial of an antibiotic compared with placebo with a sensitive organism. NNTs of 2 to 5 are indicative of high efficacy (as, for instance, with analgesics in acute pain [9]).

Imiquimod is a potent stimulator of cytokines, particularly interferons. A review of the mechanism of action of imiquimod is beyond the scope of this article, but there is an excellent account by Stanley [10].

\section{Methods}

The search strategy is described in supplementary file 1. Electronic searches were supplemented with information from reviews $[2,10]$. QUORUM guidelines were followed [11]. Included were full publications of randomised trials that investigated imiquimod in the treatment of genital warts, and which had efficacy or safety data. Excluded were reviews with clinical information published in a fuller form elsewhere, studies with purely biochemical or immunological information, abstracts, or studies that used imiquimod for treating conditions other than genital warts.

Each report was scored for quality using a three item, 15 score, quality scale [12]. Points were awarded to studies according to whether they were randomised and double blind and mentioned withdrawals or drop-outs from the study. An additional point was awarded if both the method of randomisation and double blinding was described and was appropriate.

From each trial was extracted the number of patients treated per group, dosing regimes, study design, and the number of patients with efficacy and/or safety outcomes. RAM extracted the data into tables, and these were then read and checked by other authors. Prior definitions of outcomes of interest included those describing treatment efficacy (wart clearance) and those describing adverse events. For adverse events, treatment-related adverse event withdrawal has been shown to be the most commonly reported, and probably most useful measure [13], but the intention was also to combine information for particular local and systemic adverse events if reported in ways that allowed this. Three main efficacy outcomes and three harm outcomes were therefore sought from the trials, using the denominator of the number of patients randomised so that results were on an intention-to-treat basis. The main outcomes sought were the number of patients with:

- Complete clearance of warts present at the start of treatment.

- At least 50\% reduction in wart area.

- Complete clearance of warts and no recurrence thereafter.

- Patients withdrawing from the study because of (reported) treatment-related adverse effects.

- Patients withdrawing from the study because of lack of efficacy.

- Patients with particular adverse effects. 
There were additional minor outcomes of interest. One was the number of new warts that appeared after treatment started, and the clearance of these warts during treatment; clearly this could not be done on an intentionto-treat basis. Recurrence was also reported as the rate of recurrence in those patients with initial complete clearance. Again, this could not be analysed on an intentionto-treat basis.

Confidence intervals (95\%) for single samples were calculated for proportions [14]. Relative benefit and relative risk estimates were calculated with $95 \%$ confidence intervals using a fixed effects model [15]. Heterogeneity tests were not used as they have previously been shown to be unhelpful [16]. Publication bias was not assessed using funnel plots as these tests have been shown to be unhelpful $[17,18]$. The number needed to treat (NNT) and number needed to harm (NNH) with confidence intervals were calculated by the method of Cook and Sackett [19]. Relative benefit or risk was considered to be statistically significant when the $95 \%$ confidence interval did not include 1. NNT or NNH values were only calculated when the relative risk or benefit was statistically significant, and are reported with the 95\% confidence interval. Statistical significance of any difference between numbers needed to treat for different doses or between men and women was assumed if there was no overlap of the confidence intervals, and additionally tested using the $\mathrm{z}$ statistic [20].Calculations were performed using Microsoft Excel 98 on a Power Macintosh G4.

\section{Results}

A literature search found 16 reports for which full copies were obtained and read. Of these, 10 were excluded (supplementary file 2) because they did not meet the inclusion criteria. A number of these were review or other articles with clinical information duplicated in other publications, but always with attribution. Where information on the same patients was available in duplicate reports, we used studies with the fullest amount of clinical information.

Details of the six included studies are given in supplementary file 3. All six studies were conducted in the setting of home administration after initial professional examination and advice. Five of the studies were explicit that not other treatment was allowed within at least four weeks of the start of the trial. Wart location was predominantly vulvar or perianal in women, and penile or perianal in men. Five studies were conducted in North America or the UK using 5\% or $1 \%$ imiquimod cream (Aldara, 3M Pharmaceuticals) [21,22,23,24,25], and one [26] was conducted in Pakistan using a $2 \%$ cream manufactured locally. This latter study was included despite lack of clarity about the formulation or nature of what was being applied (the title of the article indicated an imiquimod analogue was used). The prior intention, though, was to perform sensitivity analysis, particularly with regard to dose. Four studies used application schedules of 6-10 hours overnight three times a week [21, $23,24,25]$, one for 24 hours three times a week [22], and the other ( $2 \%$ cream) applied twice a day for five consecutive days with a two-day rest period before repeat treatment. Duration of treatment was predominantly for 16 weeks (one study was 8 weeks with 24 hours duration for each application [22]), with a further follow up of 10 to 16 weeks to check for recurrence.

All the trials were described as randomised and double blind. No study described the randomisation process, and two disclosed that treatment and placebo were visually identical. All adequately described the number and reasons for withdrawals or dropouts from the trials. Quality scores were therefore 3 in four and 4 in two studies (supplementary file 3 ) out of a maximum possible score of 5 and a minimum possible score of 1 .

All the studies described the diagnostic procedures to diagnose genital warts. This was usually (four of five studies) a combination of clinical examination supplemented by biopsy and histology. One study used genetic techniques to identify HPV 6 and 11 [26]. In all studies but one wart area was assessed by inspection and mapping, and by photography, so that warts present initially could be identified and their area calculated and measured over time, and any new warts similarly identified and area measured [26].

The study populations were all adults. Five included men and women, though one had more than $90 \%$ men [22]. One study examined only women [26]. HIV seronegativity was a requirement in five studies, and the other examined only patients with HIV infection [24].

\section{Efficacy}

\section{Complete wart clearance}

Pooling of data was considered for all the five studies with immunocompetent patients (and excluding the one study with HIV-infected patients [24]). Sensitivity analyses were performed by concentration of imiquimod, and by sex (using Beutner et al, 1998b [22] as data for men, who constituted over $90 \%$ of the population investigated). There was neither sufficient information (in terms of number of trials) nor difference in treatments (duration, intensity, and subsequent follow up for recurrence) to justify separate analyses. 


\begin{tabular}{|c|c|c|c|c|c|c|c|}
\hline \multirow[b]{3}{*}{ Outcome } & \multirow[b]{3}{*}{$\begin{array}{l}\text { Number } \\
\text { of trials }\end{array}$} & \multicolumn{4}{|c|}{$\begin{array}{l}\text { outcome achieved } \\
\text { with }\end{array}$} & \multirow[b]{3}{*}{$\begin{array}{l}\text { Relative benefit } \\
\qquad(95 \% \mathrm{Cl})\end{array}$} & \multirow[b]{3}{*}{ NNT $(95 \% \mathrm{Cl})$} \\
\hline & & \multicolumn{2}{|r|}{ Active } & \multicolumn{2}{|c|}{ Placebo } & & \\
\hline & & $\begin{array}{l}\text { Numberl } \\
\text { total }\end{array}$ & $\begin{array}{l}\text { Percent } \\
(95 \% \mathrm{Cl})\end{array}$ & $\begin{array}{l}\text { Numberl } \\
\text { total }\end{array}$ & $\begin{array}{l}\text { Percent } \\
(95 \% \mathrm{Cl})\end{array}$ & & \\
\hline \multicolumn{8}{|l|}{ Complete clearance of warts } \\
\hline $\begin{array}{l}\text { In all patients treated with imiquimod } \\
\text { (highest dose) }\end{array}$ & 5 & $153 / 303$ & 51 (45 to 56$)$ & $16 / 285$ & $6(3$ to 8$)$ & $8.3(5.2$ to 13$)$ & $2.2(2.0$ to 2.6$)$ \\
\hline In patients treated with $5 \%$ imiquimod & 4 & $128 / 273$ & 47 (4I to 53$)$ & $15 / 255$ & 6 (3 to 9) & 7.3 (4.5 to 12$)$ & $2.5(2.1$ to 2.9$)$ \\
\hline In patients treated with $1 \%$ imiquimod & 2 & $34 / 192$ & $18(12$ to 23$)$ & $14 / 195$ & 7 (4 to II) & 2.4 (I.4 to 4.4$)$ & 9.5 (5.9 to 25$)$ \\
\hline $\begin{array}{l}\text { In women treated with imiquimod (high- } \\
\text { est dose) }\end{array}$ & 3 & $85 / 118$ & 72 (64 to 80$)$ & $12 / 112$ & II (5 to 16$)$ & $6.6(3.8$ to 11$)$ & 1.6 (1.4 to 2.0$)$ \\
\hline $\begin{array}{l}\text { In men treated with imiquimod (highest } \\
\text { dose) }\end{array}$ & 3 & $61 / 166$ & 37 (29 to 44$)$ & $4 / 171$ & $2(1$ to 5$)$ & I5 (5.8 to 4 I) & 2.9 (2.4 to 3.7$)$ \\
\hline \multicolumn{8}{|l|}{ At least $\mathbf{5 0 \%}$ clearance of warts } \\
\hline In patients treated with $5 \%$ imiquimod & 4 & $197 / 273$ & $72(67$ to 78$)$ & $50 / 255$ & 20 (15 to 25$)$ & $3.6(2.8$ to 4.6$)$ & $1.9(1.7$ to 2.2$)$ \\
\hline In patients treated with $1 \%$ imiquimod & 2 & $68 / 198$ & 34 (28 to 4 I) & $45 / 195$ & 23 (17 to 29$)$ & $1.5(1.1$ to 2.1$)$ & $8.1(4.7$ to 30$)$ \\
\hline $\begin{array}{l}\text { In women treated with imiquimod (high- } \\
\text { est dose) }\end{array}$ & 1 & $39 / 46$ & 85 (74 to 95$)$ & $15 / 40$ & 38 (22 to 53$)$ & 2.3 (1.5 to 3.4$)$ & $2.1(1.5$ to 3.4$)$ \\
\hline $\begin{array}{l}\text { In men treated with imiquimod (highest } \\
\text { dose) }\end{array}$ & 2 & $78 / 114$ & 68 (60 to 77$)$ & $17 / 117$ & $15(8$ to 21$)$ & $4.6(2.9$ to 7.2$)$ & 1.9 (1.6 to 2.3$)$ \\
\hline \multicolumn{8}{|l|}{$\begin{array}{l}\text { Warts completely cleared and not } \\
\text { recurred }\end{array}$} \\
\hline In patients treated with $5 \%$ imiquimod & 3 & $94 / 254$ & 37 (3I to 43$)$ & $10 / 253$ & $4(2$ to 6$)$ & 9.0 (4.9 to 17$)$ & $3.0(2.5$ to 3.8$)$ \\
\hline In patients treated with $1 \%$ imiquimod & 2 & $28 / 192$ & $15(10$ to 20$)$ & $9 / 195$ & $5(2$ to 8$)$ & 2.9 (1.5 to 5.9$)$ & $10(6.4$ to 26$)$ \\
\hline \multicolumn{8}{|l|}{ New warts completely cleared } \\
\hline In patients treated with $5 \%$ imiquimod & 2 & $|6 / 4|$ & $39(24$ to 54$)$ & $16 / 78$ & $21(12$ to 30$)$ & $2.0(1.1$ to 3.7$)$ & $5.4(2.8$ to 91$)$ \\
\hline
\end{tabular}

Outcomes are reported for various doses of imiquimod and durations of treatment. When $5 \%$ and $1 \%$ imiquimod was used in a singe trial, the $5 \%$ results are compared with placebo unless specified otherwise. Only studies with $\mathrm{HIV}$-negative patients have been pooled $\mathrm{Cl}=\mathrm{confidence} \mathrm{interval;}$ NNT = number needed to treat

Complete clearance of warts was reported in all five trials of HIV negative patients (Figure 1). This was achieved in $51 \%$ of patients ( $95 \%$ confidence interval $45 \%$ to $56 \%$ ) treated with the highest concentration of imiquimod ( $2 \%$ in one trial, $5 \%$ in four), but in only $6 \%$ (3\% to $8 \%$ ) of patients treated with placebo cream. The NNT was 2.2 (95\% confidence interval 2.0 to 2.6). This means that two patients have to be treated with $2 \%$ or $5 \%$ imiquimod for 8 to 16 weeks for one of them to have warts completely cleared (Table 1). The results for $5 \%$ imiquimod in four trials were similar. Substantially fewer patients were cured with $1 \%$ imiquimod in two trials, and for this concentration the NNT was 9.5 (5.9 to 25). In three trials results were more favourable for women (mean $72 \%$ clearance) than men (mean $37 \%$ clearance).

Imiquimod 5\% cream was significantly more effective than imiquimod 1\% cream for complete wart clearance (Table 1), with no overlap of confidence intervals of the NNTs $(\mathrm{z}=6.5, \mathrm{p}<0.001)$. Imiquimod was more effective in women $(72 \%$ of whom had complete wart clearance by the end of treatment) than in men (37\%); there was no overlap of confidence intervals of the NNTs $(\mathrm{z}=4.2, \mathrm{p}<$ o.001).

\section{At least $50 \%$ reduction in wart area}

This outcome was reported in four trials with imiquimod $5 \%$, where $72 \%(67 \%$ to $78 \%)$ of patients had the outcome, compared with $20 \%$ (15\% to $25 \%$ ) with placebo. The NNT was 1.9 (1.7 to 2.2). This means that two patients have to be treated with $5 \%$ imiquimod for 8 to 16 weeks for one of them to have wart area reduced by at least 50\% (Table 1). Substantially fewer patients were cured with $1 \%$ imiquimod in two trials, and for this concentration the NNT was 8.1 ( 4.7 to 30 ). The number of trials and patients available for analysis by sex was small (Table 1), and results were more favourable for women (mean $85 \%$ with at least $50 \%$ reduction) than men (mean $68 \%$ ).Imiquimod $5 \%$ cream was significantly more effective than imiquimod 1\% cream in producing at least 50\% reduction in wart area (Table 1 ), with no overlap of confidence intervals of the NNTs $(\mathrm{z}=7.1, \mathrm{p}<0.001)$. Imiq- 
Percent of warts cleared with imiquimod

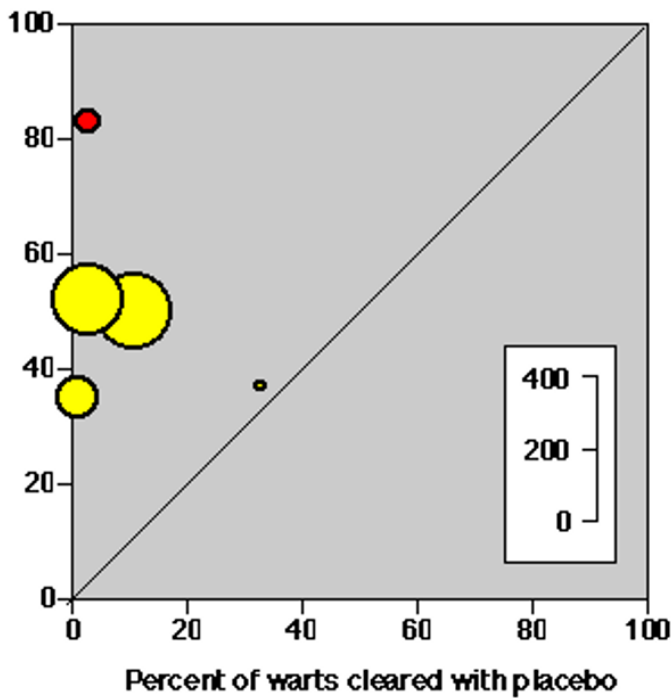

Figure I

Warts cleared at end of treatment with imiquimod 5\% (yellow) or $2 \%$ (red). The size of the symbol is proportional to the size of the study.

uimod was more effective in women (85\% of whom had at least a $50 \%$ reduction in wart area) than in men (37\%); there was overlap of confidence intervals of the NNTs. There were too few trials to give confidence to this conclusion, however (Table 1).

\section{Warts completely cured and not recurred}

Because the object of treatment is clearance of warts without recurrence, this outcome was sought. Three trials with $5 \%$ imiquimod reported the number of patients randomised, the number completely cleared at the end of treatment, and the number of those who were completely clear at the end of treatment and in whom new warts were observed in the subsequent 10-16 weeks. Consequently the number of patients fulfilling this outcome could be calculated, with the number of patients randomised as the intention to treat denominator.

Warts were completely cured and did not recur in $37 \%$ (31\% to $43 \%$ ) of patients treated with imiquimod 5\%, and $4 \%$ (2\% to $6 \%$ ) of patients treated with placebo. The NNT was 3.0 (2.5 to 3.8 ). This means that three patients have to be treated with $5 \%$ imiquimod for 8 to 16 weeks for one of them to have warts completely cleared, and for them not to recur (Table 1). Substantially fewer patients were cured with $1 \%$ imiquimod in two trials, and for this concentration the NNT was 10 (6.4 to 26).

Imiquimod 5\% cream was significantly more effective than imiquimod 1\% cream in ensuring that warts were completely cleared by the end of treatment and did not recur (Table 1), with no overlap of confidence intervals of the NNTs $(\mathrm{z}=5.2, \mathrm{p}<0.001)$.

\section{New warts}

Three studies also reported on the number of new warts that appeared after the start of the study and before the end of treatment. New warts appeared in 30\% (24\% to $36 \%)$ of those treated with imiquimod 5\%, 48\% (41\% to $55 \%)$ of those treated with imiquimod 1\%, and $48 \%(42 \%$ to $55 \%$ ) of those treated with placebo. The proportion of new warts appearing since the study started and which had completely cleared by the end was $39 \%$ (24\% to $54 \%$; 41 patients) with $5 \%$ imiquimod, was $21 \%$ (12\% to $30 \%$; 78 patients) with placebo, and the NNT was 5.4 (2.8 to 91) (Table 1). This means that for every five patients with new warts appearing after the trial started, one more had the new warts cleared by the end of treatment than with placebo.

\section{Recurrence}

Recurrence (defined as the number of patients with new warts when previously completely cleared) in the 10-16 weeks after the end of the treatment phase was reported in three trials. Recurrence occurred in 18/112 patients (16\%; 95\% confidence interval $9 \%$ to $23 \%$ ) of those treated with imiquimod $5 \%, 2 / 30$ ( $7 \% ; 2 \%$ to $16 \%)$ of those treated with imiquimod $1 \%$, and $1 / 13$ (8\%; $-7 \%$ to $22 \%$ ) of those treated with placebo. For the three large trials $[21,22,23] 121 / 254$ patients had warts cleared at the end of treatment with $5 \%$ imiquimod, and only $27 / 121$ (22\%) of these had a recurrence or reinfection.

\section{Using random effects}

Because studies were clinically homogeneous a fixed-effects model was used to calculate relative benefits. Using a random effects model would have made no appreciable difference, apart from the outcome of the number of patients with $50 \%$ reduction in wart area with $1 \%$ imiquimod. The relative benefit of 1.5 (1.1 to 2.1) found with a fixed effects model would have changed to 1.5 (1.0 to 2.4) by using random effects.

\section{Adverse events}

In supplementary file 4 details of how adverse events were measured are shown, together with adverse events and withdrawals. Most of the studies assessed local skin reactions at the site of cream application using patient 
and physician scales, though not all of the outcomes were reported uniformly.

Commonly reported adverse events were localised itching, erythema, burning and erosion or excoriation. The rates of moderate or severe adverse effects are given in supplementary file 4. They were not pooled because it was not clear that the outcomes were the same, the numbers of patients included as the denominator was unclear, and information was not always given for imiquimod and placebo. Numbers needed to harm could not be calculated, nor could an overall weighted percentage of patients with moderate or severe reactions. Studies indicated that when local reactions caused problems, a temporary "holiday" from treatment reversed them, upon which treatment began again.

Withdrawals and the reason for withdrawals were clearly described. All causes of withdrawal were given, predominantly with assignment to treatment group. Treatmentrelated withdrawal included withdrawal because of adverse effects, and because of lack of effect. Adverse effect withdrawals were also given, so that withdrawal rates because of lack of effect could be calculated.

For adverse event withdrawal, there was no difference between placebo and imiquimod at all concentrations (relative risk 1.7; 95\% confidence interval 0.4 to 9.9) or $5 \%$ cream (relative risk 1.9 ; 0.4 to 10 , Table 2 ). Withdrawal because of lack of efficacy was described in five studies, and pooling information from the highest concentration of imiquimod in each trial (2\% or $5 \%$ ) showed that $1.7 \%$ (0.3\% to $3.1 \%$ ) of patients withdrew because of lack of effect with imiquimod, compared with $7.4 \%(4.3 \%$ to $11 \%$ ) with placebo. The relative risk was 0.3 (0.1 to 0.7 ) and the NNH was -18 ( -11 to -48$)$. This means that for every 18 patients treated with imiquimod $2 \%$ or $5 \%$, one fewer will discontinue treatment because of lack of effect than would have happened with placebo.

\section{Imiquimod in hiv-infected patients}

The single study that was conducted in this setting [24] showed little benefit in terms of warts completely cleared (supplementary file 3). The proportion with warts area reduced by at least 50\% was 38\%, significantly better than with placebo at $14 \%$ (supplementary file 3 ). New wart appearance was similar. Adverse events were similar to non-HIV infected individuals, though one man had swelling and soreness of the prepuce and glans penis sufficient to necessitate circumcision.

\section{Discussion}

This quantitative systematic review demonstrates that imiquimod is effective in the self-treatment of genital warts at home, at the cost of some adverse effects associated with enhanced inflammatory reactions that were reversible when treatment was stopped temporarily. Studies were clinically homogeneous in terms of patient inclusion criteria and those who were excluded. For instance, the five studies used for data pooling all excluded patients with HIV infection. They were also homogeneous in terms of the treatment periods (8-16 weeks). Most used thrice-weekly applications though one [26] used daily application for five days with a two-day rest. In the latter case the maximum number of applications was 60, as compared to 48 in most others. The exception was a study that used a 24-hour application three times a week [22], but in that case the duration was only eight weeks. Maximum exposure to imiquimod was therefore similar.

Table 2: Pooled data on adverse events

\begin{tabular}{|c|c|c|c|c|c|c|c|}
\hline \multirow[b]{3}{*}{ Outcome } & \multirow[b]{3}{*}{$\begin{array}{l}\text { Number } \\
\text { of trials }\end{array}$} & \multicolumn{4}{|c|}{$\begin{array}{l}\text { Outcome achieved } \\
\text { with }\end{array}$} & \multirow[b]{3}{*}{ Relative $(95 \% \mathrm{Cl})$} & \multirow[b]{3}{*}{$\mathrm{NNH}(95 \% \mathrm{Cl})$} \\
\hline & & \multicolumn{2}{|c|}{ Active } & \multicolumn{2}{|c|}{ Placebo } & & \\
\hline & & $\begin{array}{l}\text { Numberl } \\
\text { total }\end{array}$ & $\begin{array}{l}\text { Percent } \\
(95 \% \text { CD) }\end{array}$ & $\begin{array}{l}\text { Number/ } \\
\text { total }\end{array}$ & $\begin{array}{l}\text { Percent } \\
(95 \% \mathrm{Cl})\end{array}$ & & \\
\hline $\begin{array}{l}\text { Adverse event withdrawal (all concentra- } \\
\text { tions of imiquimod) }\end{array}$ & 4 & $5 / 284$ & $\begin{array}{l}1.8(0.2 \text { to } \\
3.4)\end{array}$ & $0 / 186$ & $0(0$ to 0$)$ & $1.7(0.4$ to 9.9$)$ & not calculated \\
\hline Adverse event withdrawel (imiquimod 5\%) & 3 & $4 / 164$ & $\begin{array}{c}2.4(0.0 \text { to } \\
4.8)\end{array}$ & $0 / 156$ & $0(0$ to 0$)$ & $1.9(0.4$ to 10$)$ & not calculated \\
\hline $\begin{array}{l}\text { Lack of efficacy withdrawal (imiquimod } 2 \% \\
\text { or } 5 \% \text { ) }\end{array}$ & 5 & $5 / 303$ & $\begin{array}{c}1.7(0.3 \text { to } \\
3.1)\end{array}$ & $21 / 285$ & $\begin{array}{l}7.4 \text { ( } 4.3 \text { to } \\
\text { II) }\end{array}$ & $0.3(0.1$ to 0.7$)$ & $-18(-1 \mid$ to -48$)$ \\
\hline
\end{tabular}

The number needed to harm $(\mathrm{NNH})$ describes the number of patients who have to be treated for one to have treatment-specific harm compared with placebo. Negative figures indicate that the harm occurs less frequently with treatment than placebo. NNH was not calculated when there was no significant difference between imiquimod and placebo. $\mathrm{Cl}=$ confidence interval; $\mathrm{NNH}=$ number needed to harm 


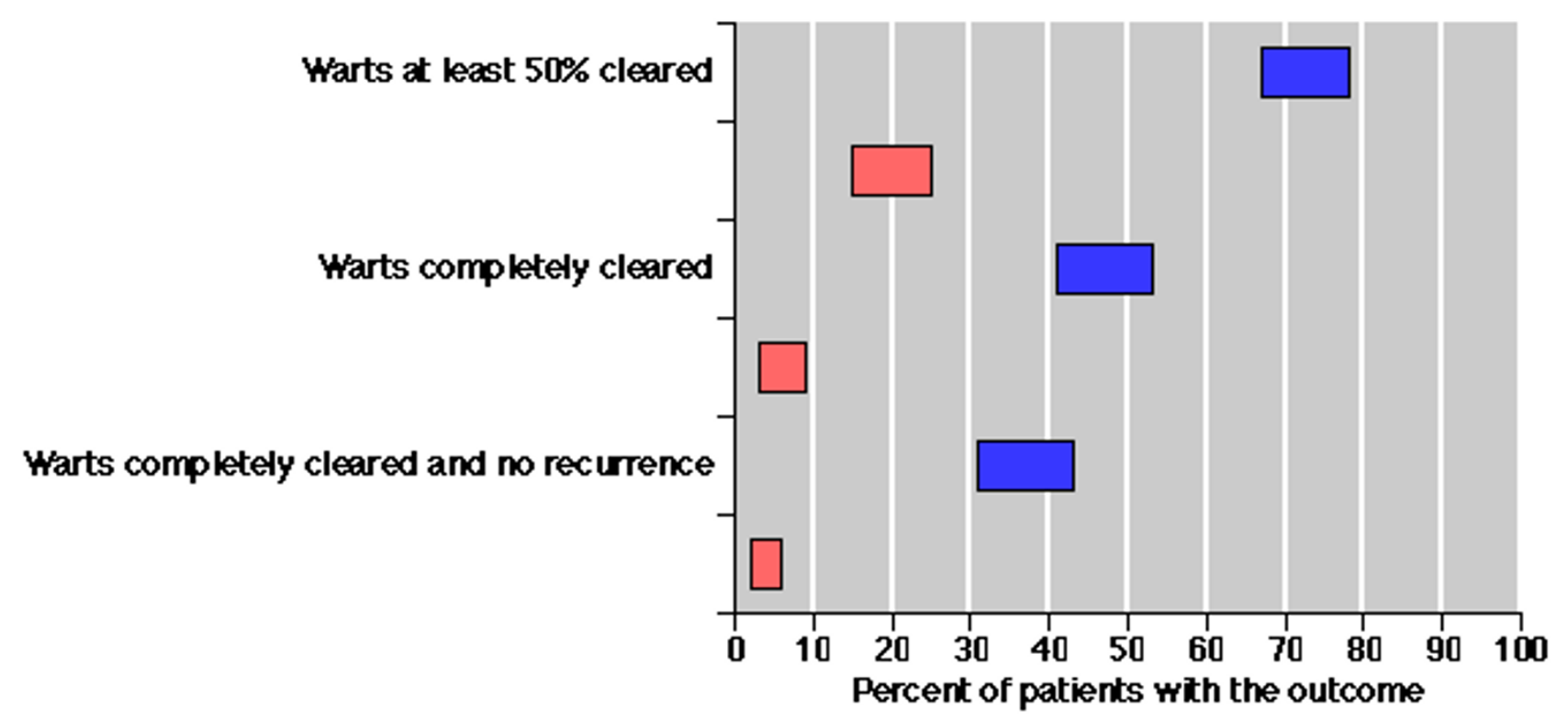

Figure 2

Percentage of patients with different outcomes with placebo (pink) and imiquimod (blue)

A possible source of heterogeneity was the source of the imiquimod used in the trials. For five trials this was the formulation produced by $3 \mathrm{M}$ Pharmaceuticals, at $1 \%$ or $5 \%$ strength. One trial used a different strength (2\%) [26], and unclear formulation. Sensitivity analysis therefore examined the highest concentration of imiquimod in all trials, that is data on $2 \%$ or $5 \%$ creams (Figure 1), and with $5 \%$ and $1 \%$ imiquimod creams separately.

Outcomes used to demonstrate efficacy were also homogeneous. These were patients with warts completely cleared, or with wart area reduced by half. Wart measurement was uniformly objective, with mapping and even with photographs to ensure objectivity. One outcome not reported, but one that could be inferred, was that of patients with warts completely cleared by the end of treatment, and with no recurrence of warts during the 10-16 weeks of follow up.

Numbers needed to treat for these outcomes were 2 (complete clearance or at least 50\% reduction in wart area) or 3 (warts completely cleared by the end of treatment, and with no recurrence). This occurred despite very different absolute percentages of patients achieving the outcome, because placebo rates were high (20\%) with the easiest outcome (at least 50\% reduction in wart area) and as low as $4 \%$ with the hardest (warts completely cleared by the end of treatment, and with no recurrence). This is shown in Figure 2. Complete wart clearance by the end of treatment was 40-50\% with 5\% imiquimod (Figure 2, Table 1), with application three times a week. This is slightly less than the $62 \%$ clearance rate seen in a small non-randomised open study comparing this application strategy with daily application [27] published after searching had been completed.

There was a clear concentration-response, with 5\% imiquimod consistently achieving higher clearance rates and lower NNTs than 1\% (Table 1). Results for women were consistently better than for men for complete clearance, though not for at least 50\% reduction in wart area (Table 1).

Recurrence of warts was described for patients in whom warts had cleared. The results of the pooled analysis tell us that about $50 \%$ of patients will have their warts cleared with $5 \%$ imiquimod, and that $40 \%$ will have warts cleared and there will be no recurrence. The implication is that for 4 out of 5 patients in whom warts clearance is achieved, no recurrence will occur. For the three 
large trials $[21,22,23] 121 / 254$ patients had warts cleared at the end of treatment with $5 \%$ imiquimod, and only 27/ 121 (22\%) of these has a recurrence. It is unclear whether this recurrence rate of $22 \%$ can be compared with the higher recurrence rates (up to 95\% with laser therapy) quoted for other treatments [7].

Adverse events were well recorded, especially withdrawal due to lack of effect and adverse events [13], and the methods used to collect adverse event information given in the five large trials (supplementary file 4). Adverse events were actively sought at clinic visits in most studies, and diaries and prompts can lead to increased reporting of adverse events [28]. Local events related to enhancement of the inflammatory response, erythema, itching, burning, irritation and tenderness were common (supplementary file 4), even at a moderate or severe intensity. Adverse events caused few patients to withdraw (about 2\%), and this was not significantly different from placebo. Fewer patients given imiquimod withdrew because of lack of efficacy (Table 2).

The quality of the evidence was good on several counts. Not only was there clinical homogeneity, but the quality scores were 3 or 4 , and scores of 3 or more have been shown $[29,30]$ to be associated with less likelihood of bias. Moreover for most of the efficacy outcomes there was enough data and a large enough effect to make it likely that the results would be free of any chance effects [31]. Efficacy was robust to sensitivity analysis, and there was a dose-response.

What the review cannot tell us is whether there are different patient groups (other than men and women) who might differentially benefit. For instance, there was no opportunity to perform an analysis based on the severity of the warts by number or area. That analysis could only be done using detailed information on individual patients. Nor was it possible to derive any information on the many practical issues that surround management of genital warts, such as personal hygiene, the ability to see the warts to adequately apply the treatments, unprotected sexual intercourse, clothing or other infections. Many of these practical problems may be beyond the scope of randomised trials, and therefore reviews of them.

The results of this systematic review complement guidelines for the diagnosis and treatment of genital warts in primary care $[3,4]$. They demonstrate imiquimod to be effective in home application, though not in patients with HIV infection with the evidence presently available [24]. Rates of first attacks of genital warts have been rising for a decade [32], and an average primary care group of 100,000 population will have about 240 such cases a year, with as many again of recurrences and reregistered cases [32]. Pressures on hospital-led clinics, or their inaccessibility in rural areas, together with the availability of treatments like imiquimod that can be used at home, makes recognition of its role in primary care sensible [4].

Practitioners often want information about the relative efficacy and harm of different treatments for the same complaint, and, increasingly, about relative cost-effectiveness. We could not find any systematic review of other treatments for genital warts in this setting, particularly for podophyllotoxin.

\section{Additional material}

\section{Supplementary files}

File 1: Search strategy

File 2: Excluded studies

File 3: Randomised placebo-controlled trials of imiquimod cream for genital warts- efficacy

File 4: Randomised placebo-controlled trials of imiquimod cream for genital warts - adverse effects

File 1

[http://www.biomedcentral.com/content/supplementary/14712334-1-3-S1.pdf]

File 2

[http://www.biomedcentral.com/content/supplementary/14712334-1-3-S2.xIs]

File 3

[http://www.biomedcentral.com/content/supplementary/14712334-1-3-S3.xIs]

File 4

[http://www.biomedcentral.com/content/supplementary/14712334-1-3-S4.xIs]

\section{Acknowledgements}

This review was made possible by an unrestricted educational grant from 3 M Pharmaceuticals Ltd, Loughborough, Leicestershire, UK, in conjunction with Hayward MedicalCommunications a division of Hayward PLC. It was also supported by Pain Research funds.

\section{Competing interests}

DH has received one lecture fee from $3 \mathrm{M}$ (paid into Trust Funds) in the past five years.

\section{References}

I. Lamagmi TL, Hughes G, Rogers PA, et al: New cases seen at genitourinary medicine clinics: England 1998. Comm Dis Report 1998, 9 (Suppl 6): I-12

2. Richwald GA, Reitano M: New approaches to the management of external genital warts. Infect Dis Clin Pract 1999, 8:67-75

3. von Krogh G, Lacey CJ, Gross G, et al: European course on HPV associated pathology: guidelines for primary care physicians for the diagnosis and management of anogenital warts. Sex Transm Inf 2000, 76:162-8

4. Lacey C: New guidelines assist GP management of anogenital warts. Guidelines in Practice 200 I, 3:25-30 
5. Clinical Effectiveness Group (Association of Genitourinary Medicine and Medical Society for the study of Venereal Disease) : National guideline for the management of anogenital warts. Sex Transm Inf 1 999, 75 (SuppI I):S7I-5

6. Centres for Disease Control and Prevention.: Guidelines for treatment of sexually transmitted diseases. MMWR 1998, 47(RR-I): I-III

7. Centres for Disease Control and Prevention. : 1998 guidelines for treatment of sexually transmitted diseases. MMWR 1997, 47:88-95

8. McQuay HJ, Moore RA: Using numerical results from systematic reviews in clinical practice. Ann Intern Med 1997, 126:712720

9. McQuay HJ, Moore RA: An evidence-based resource for pain relief. Oxford. Oxford University Press 1998, ISBN 0-19-2627| 8-X:

10. Stanley MA: Mechanism of action of Imiquimod. Papillomavirus Report 1999, 10:23-29

II. Moher D, Cook DJ, Eastwood S, et al: Improving the quality of reports of meta-analyses of randomised controlled trials: the QUORUM statement. Lancet 1999, 354:1896-1900

12. Jadad AR, Moore RA, Carroll D, Jenkinson C, Reynolds DJM, Gavaghan $D J$, McQuay $H J$ : Assessing the quality of reports of randomized clinical trials: is blinding necessary? Control Clin Trial 1996, 17:1-12

13. loannidis JP, Lau J: Completeness of safety reporting in randomized trials. An evaluation of $\mathbf{7}$ medical areas. JAMA 200I, 285:437-443

14. Gardner MJ, Altman DG: Confidence intervals rather than $\mathbf{P}$ values: estimation rather than hypothesis testing. BMJ 1986, 292:746-50

15. Morris JA Gardner M]: Calculating confidence intervals for relative risk, odds ratios and standardised ratios and rates. In Statistics with confidence - confidence intervals and statistical guidelines. Edited by Gardner, MJ and Altman DG. London: British Medical Journal, 199550-63

16. Gavaghan DJ, Moore RA, McQuay HJ: An evaluation of homogeneity tests in meta-analyses in pain using simulations of individual patient data. Pain 2000, 85:415-424

17. J Tang, JL Liu: Misleading funnel plot for detection of bias in meta-analysis. J Clin Epidemiol 2000, 53:477-484

18. Sterne JA, Gavaghan D, Egger M: Publication and related bias in meta-analysis. Power of statistical tests and prevalence in the literature . J Clin Epidemiol 2000, 53: I I 19-29

19. Cook RJ, Sackett DL: The number needed to treat: a clinically useful measure of treatment effect. BMJ 1995, 3 I 0:452-4

20. Tramèr M, Reynolds DJM, Moore RA, McQuay HJ: Effect of covert duplicate publication on meta-analysis; a case study. BMJ 1997, 3 I 5:635-40

21. Beutner KR, Tyring SK, Trofatter KF, et al: Imiquimod, a patientapplied immune-response modifier for treatment of external genital warts. Antimicrobial Agents and Chemotherapy 1998, 42:789-794

22. Beutner KR, Spruance SL, Hougham AJ, et al: Treatment of genital warts with an immune-response modifier (imiquimod). J $A M$ Acad Dermatol 1998, 38:230-239

23. Edwards L, Ferenczy A, Eron L, et al: Self-administered topical $\mathbf{5 \%}$ imiquimod cream for external anogenital warts. Arch Dermatol 1998, 134:25-30

24. Gilson RJ, Shupack JL, Fried-Kien AE, et al: A randomized,controlled, safety study using imiquimod for the topical treatment of anogenital warts in HIV-infected patients. AIDS 1999, 1 3:2397-2404

25. Tyring SK, Arany I, Stanley MA, et al: A randomized, controlled, molecular study of condylomata acuminata clearance during treatment with imiquimod. J Infect Dis 1998, 178:55I-555

26. Syed T, Ahmadpour OA, Ahmad SA, Ahmad SH: Management of female genital warts with an analog of imiquimod $2 \%$ in cream: a randomized, double-blind, placebo-controlled study. I Dermatol 1998, 25:429-433

27. Gollnick H, Barasso R, Jappe U, et al: Safety and efficacy of imiquimod $5 \%$ cream in the treatment of penile genital warts in uncircumcised men when applied three times weekly or once per day. Int J STD \& AIDS 200I, I 2:22-28

28. Edwards JE, McQuay HJ, Moore RA, Collins SL: Reporting of adverse effects in clinical trials should be improved. Lessons from acute postoperative pain. I Pain Symptom Manag 1999, 18:427-37

29. Khan KS, Daya S, Jadad AR: The importance of quality of primary studies in producing unbiased systematic reviews. Arch Intern Med 1996, 156:661-6

30. Moher D, Pham B, Jones A, et al: Does quality of reports of randomised trials affect estimates of intervention efficacy reported in meta-analyses? Lancet 1998, 352:609-613

31. Moore RA, Gavaghan D, Tramèr MR, et al: Size is everything large amounts of information are needed to overcome random effects in estimating direction and magnitude of treatment effects. Pain 1998, 78:217-220

32. PHLS, DHSS\&PS and the Scottish ISD(S)5 Collaborative Group. : Trends in sexually transmitted infections in the United Kingdom, 1 990-1 999. London: Public Health Laboratory Service, 2000

\section{Pre-publication history}

The pre-publication history for this paper can be accessed here:

http://www.biomedcentral.com/content/backmatter/ 1471-2334-1-3-b1.pdf

Publish with BioMedcentral and every scientist can read your work free of charge

"BioMedcentral will be the most significant development for disseminating the results of biomedical research in our lifetime." Paul Nurse, Director-General, Imperial Cancer Research Fund

Publish with BMc and your research papers will be:

- available free of charge to the entire biomedical community

- peer reviewed and published immediately upon acceptance

- cited in PubMed and archived on PubMed Central

- yours - you keep the copyright

Submit your manuscript here:

http://www.biomedcentral.com/manuscript/
BioMedcentral.com

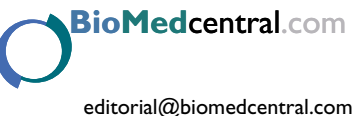

